\title{
Anna Arfelli-Galli
}

\section{The Primary Intersubjectivity and the Gestalt Theory}

\section{Background}

This paper will briefly illustrate the studies in which three scholars, Carlos Gomez, Louis Sander, and Daniel Stern, have explicitly referred to the theoretical principles of the Gestalt theory, in support of their interpretations of the development of the adult-child relationship in the first year of life. ${ }^{1}$

Reference to the Gestalt theory is made possible by the unit of analysis chosen by the three authors, i.e., the interpersonal relationship. The designated terminology also derives from this unit: moments of meeting and gestalts of the flow of sequencing and expectancy, whose development between 0 and 3 years has been studied by Sander; affect attunement and protoconversation, studied in its multimedia components by Stern; the discovering and sharing of the person's focus of attention and practical conceptualization, since the first appearance of joint attention, around which Gomez bases his considerations. ${ }^{2}$

These studies support the Gestalt viewpoint that the "I" develops within the "Us", in "a dynamic interdependency within social situations."

\section{Early Interactions}

In the study of the first year of life, much has been debated about "when" the relationship between the infant and caregiver can be considered the encounter of two inner worlds, in Gestalt terms, when the infant's experience (Erlebnis) can be interpreted as the "experience of a person in relation" (Galli, 2010).

It is well known that the human infant relates to the external world by means of intentional and flexible behaviors, which are coherent with the concrete situation (Prechtl, 1990) and are different depending on whether they are addressed toward physical objects or human beings.

In this latter case, the infant displays "synchronous" and "reciprocal" behaviors, which are organized according to the specific relationship (Delafield-Butt \& Trevarthen, 2015; Trevarthen, 1974).

\footnotetext{
${ }^{1}$ Indirect references to the Gestalt theory can also be found in the study by Trevarthen (1996) but are limited to some specific problems and do not relate to theoretical constructs, for which the author refers to Gibson (1979). ${ }^{2}$ In relation to the chosen unit of analysis, the thought of the three authors differs substantially from that of the scholars of the theory of the mind and the schools of Meltzoff, Simion, and Spelke; here, the unit of analysis is monopersonal. In order to make the results of such different orientations interact fruitfully, a broad discussion would be required, starting from the methodological differences and the chosen terminology (Arfelli-Galli, 2005).
} 
Looking at Figure 1, we can ask ourselves the following: is the child attracted by the mother's eyes and does this generate our impression that the two are communicating with each other?

Or, rather, are the two engaged in an intimate contact and communicate with each other in their peculiar way?

Both interpretations are possible. But which experience can realistically be attributed to a newborn?

This question has been debated by psychologists, sociologists, neurobiologists, ethologists, clinicians, psychotherapists, and musicologists (Bråten, 1998, 2007).

Sander and Stern, clinicians and psychotherapists, have addressed these questions in their observations of the mother-infant dyad, while Gomez does this in his ethological research.

Their contributions can be appreciated better if considered in their reciprocal relationship, starting from Stern and ending with Gomez.

\section{Daniel Stern's Forms of Vitality}

Daniel Stern's research has clearly documented that, since the third month of life, the newborn actively collaborates with the mother in a synchronous and reciprocal interaction, which is organized in alternance or in unison, involving all sensory channels (Stern, 1971, 2004, 2010; Stern, Jaffe, Beebe, \& Bennett, 1975).

The behavioral patterns used by the mother to engage and maintain the newborn's attention are characterized by repetitiveness, by different intonation profiles,

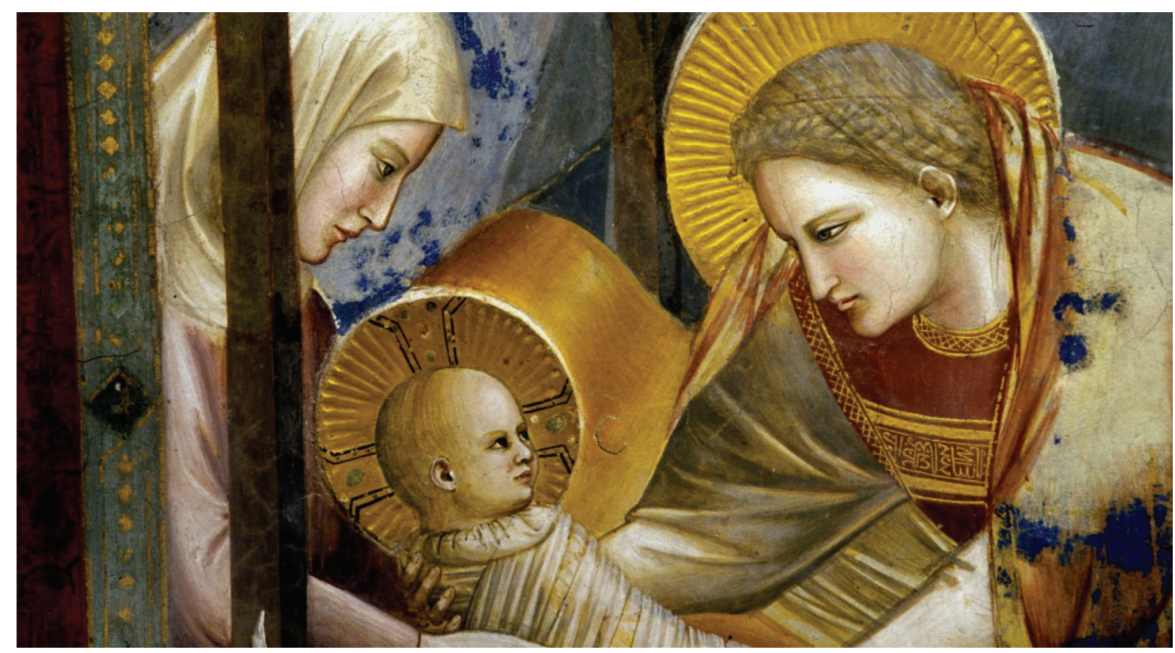

Fig. 1 Giotto - Nativity (1304-1306). Cappella degli Scrovegni, Padova. 
and by themes with or without variations, which are adapted to the newborn's affective states, as she interprets them.

Stern makes use of the term affect attunement to indicate the mother's behaviors, by which she interprets the infant's inner state and communicates that she understands him/her, that the "other" is tuned with the infant.

The interlaced arms and hands of the two partners, which Masaccio has represented in the "Madonna del solletico" (Figures 2a and 2b), represent well the

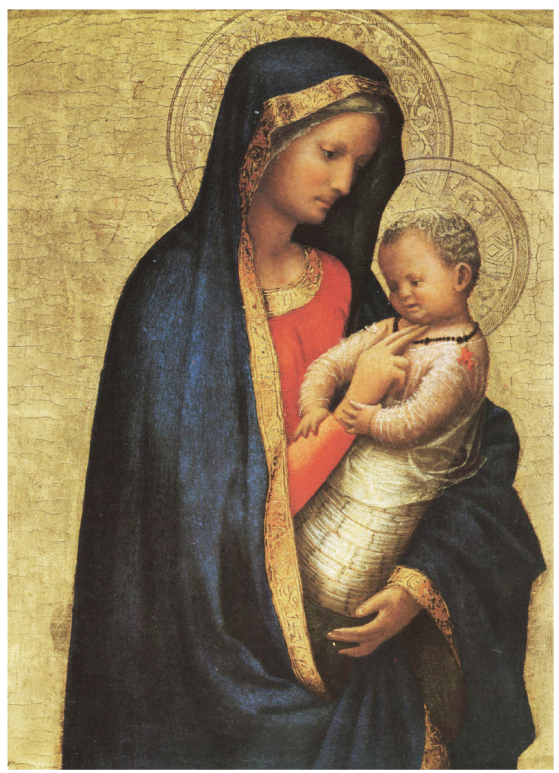

Fig. 2a Masaccio - Tickling Madonna (1426-1427). Uffizi, Firenze.

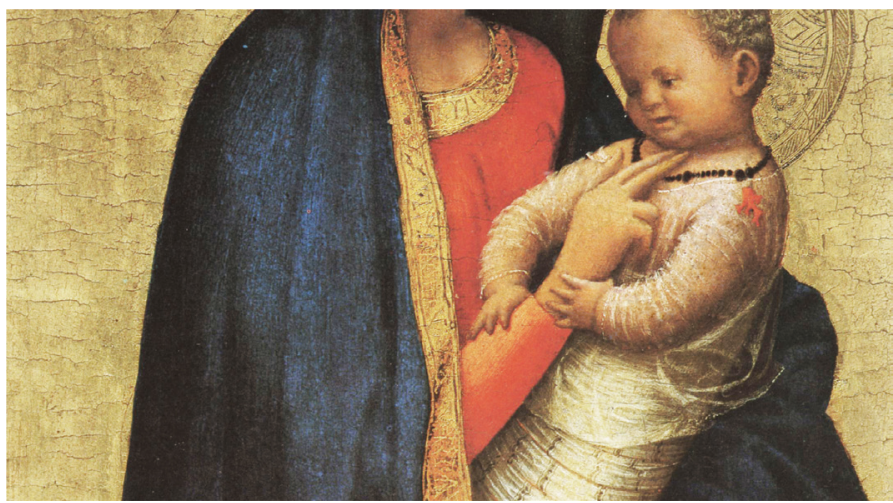

Fig. 2b Masaccio - Detail from the Tickling Madonna (1426-1427). Uffizi, Firenze. 
harmony that develops in the relationship between mother and infant through the synchrony and reciprocity of their behaviors.

To explain the correspondence between the two partners, Stern has focused his attention on the mental experience of movement: the perception of Forms of vitality, a Gestalt phenomenon present from the time of birth.

He maintains that each event of daily life is perceived as a temporal sequence developing in space with a start, a course, and an end and that this is perceived as if pointing toward a specific direction (Stern, 2010).

According to Stern, the synchrony and specificity of the mother-infant relationship, present at 3 months of life, result from the encounter of the Gestalten of the forms of vitality created in each partner's mind.

Looking at Giovanni Pisano's statue (Figures 3a and 3b), we can see the mutual correspondence of the Madonna's and child's attitudes, and we are struck by the vitality of the two persons, even though there is no movement in a statue.

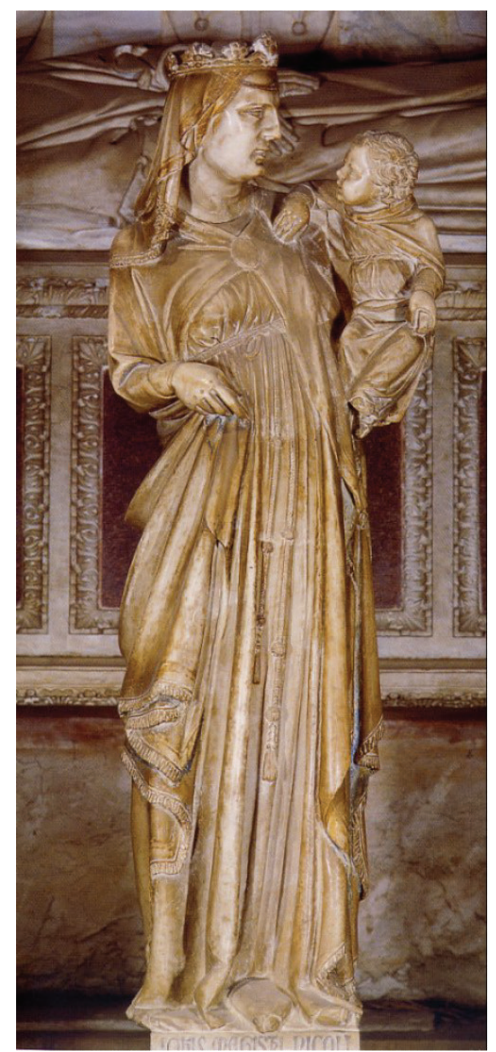

Fig. 3a Giovanni Pisano - Madonna with child (1305). Cappella degli Scrovegni, Padova. 


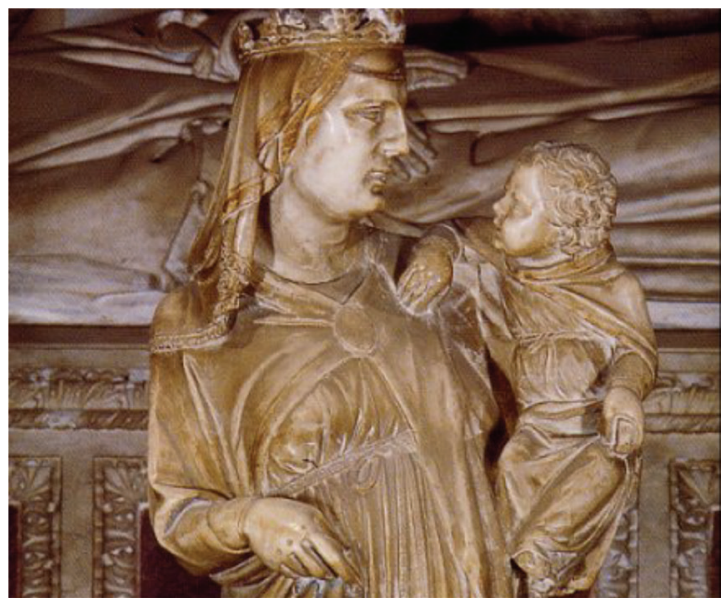

Fig. 3b Giovanni Pisano - Detail from the Madonna with child (1305). Cappella degli Scrovegni, Padova.

In Forms of Vitality (2010), Stern explicitly refers to the Gestalt psychology. He had already stated that "... the findings of Gestalt psychology are accepted, but they have not played as central a role as they might" (2004, p. 137).

He states however that: “... each separate element could be taken aside and studied in isolation".

This is in contrast with the Gestalt view, which requires respect for the encountered world, whose natural components need to be analyzed in their connection within the whole.

One gets the impression that there is a difficulty in separating the phenomenal reality from the transphenomenal reality of natural sciences.

Independently of these misunderstandings on the Gestalt theory, Stern's research has shed light on the infant's experience beginning from 3 months of age.

The forms of vitality perceived in the encountered world can help understand the complex dynamic of the encounter between two persons, in daily life, in psychotherapy, and in the development of the human infant.

Stern's research helps us understand how a relationship develops but not how such sharing occurs.

Now, what happens before 3 months of age?

\section{Sander's Beginning and Development of the "Moments of Meeting"}

Using the naturalist-explorative approach of "Infant Research", Sander et al. have followed 22 mother-infant pairs from birth to 36 months of age. 
They investigated the "negotiation" of the moments of meeting between the infant and the caregiver in organizing the different equilibria in the first 3 years of life (Sander, 2002, 2008).

The first negotiation occurs during the adjustment between the partners' sleep-wake biorhythms.

With a complex system of monitors, it was possible to compare the role of the biorhythmicity of the 24-hour neonatal state organization within different newborn-caregiver interactional systems (Sander, 2002, p. 23).

When the infant is fed by a single caregiver, equilibrium in the sleep-wake rhythms is reached within 2 weeks.

When infant cares are provided at rigidly set intervals, and by different caregivers, such equilibrium is reached some weeks later.

The results indicate that in the first 2 months of life, a unitary system develops in relation to the following:

a. the infant agency

b. the caregiver needs

c. the caregiver interpretation of the changes in state of the infant.

Already in the first weeks "... a Gestalt perception of the organism as a whole, within a context as a whole" develops (Sander, 2008, p. 185).

The following episode well highlights the Gestalt of the recurrent patterns that, already at 1 week of age, are organized in memories, and the newborn's reaction when his/her expectations are not confirmed (Sander, 2008, pp. 187-188).

On the morning of the seventh day, as the infant first showed signs of transition to the awake state, we asked the mother to put on a ski mask, but otherwise to carry out her caregiving in every way exactly as she customarily had been doing. (...)

During these procedures, the infant looked in the direction of the mother's face repeatedly without the slightest evidence of a change of state. However, now, as the mother found her comfortable position in the chair, with her infant in her left arm, and only at the moment she brought the nipple of the bottle to the infant's lips, did the effect of looking directly at the mother's face transform the infant in a dramatic surprise reaction. (...)

Its state now was one of arousal throughout, with feeding interruptions, spitting up, and choking, (...)

What this illustrates for me is that the familiarity and stability of a time framework of recurrent events and sequences also becomes a background organizing the infant's perceptual focus in the foreground that provides 
the necessary specificity of exchange and expectancy by which the infant maintains the stability of its own state regulation as a whole. (Sander, 2008, pp. 187-188)

This episode clearly exemplifies that expectations are global experiences of evolving events, oriented toward specific conclusions in a specific context, of being prepared, cleaned, or fed.

During this initial phase of biological rhythm regulation, recurrent and stable patterns develop of interactive episodes that, on their part, become organized in the gestalt of infant expectancy and of his/her next moves: the gestalts of the flow of sequencing and expectancy in both infant and caregiver.

The formation of memories on the basis of recurrent episodes generates implicit relational knowing, form of representation, considered by Sander as Gestalt.

The nervous system's ability of forming units supports Sander's opinion that, since birth, the organization of the interactions within the dyad is based on the convergence of two spheres of coherence. As an effective demonstration of the brain's ability to organize a Gestalt, Sander refers to the studies of Kanizsa (1987) on optical illusion (Figure 4) and Prechtl's (1990) studies on general movements.

We can begin at that highly complex level of brain function, one that provides a background for perception, the construction of the gestalt. A familiar example is the Kanizsa figure, in which we "see" a triangle when there are only three correctly angled dots on the page. (Sander, 2008, p. 198)

... The profound significance of this elemental capacity of the brain is better illustrated in Heinz Prechtl's newborn research design for assessing the central nervous system... (...)

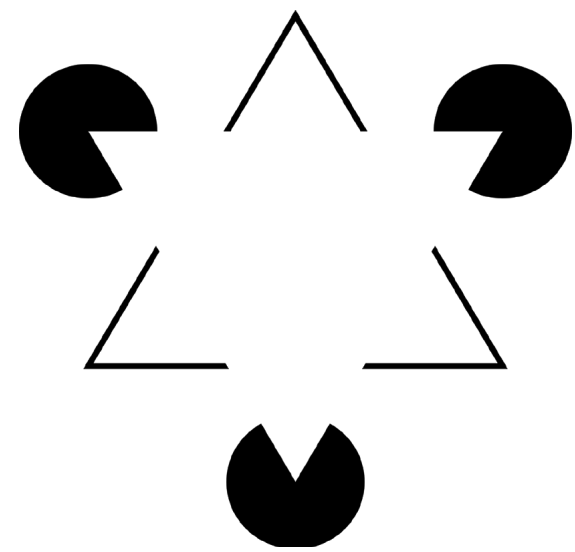

Fig. 4 In Kanizsa's triangle, we "see" a white triangle when there are only three correctly angled dots on the page. 
We can think of adaptation at the level of the organization of human consciousness in early development as the fitting together of two spheres of coherence, the gestalts of the flow of sequencing and expectancy in both infant and caregiver. (Sander, 2008, p. 198)

An important requirement for this specificity, however, lies in the organization of the focus of attention in both infant and mother, in beginning and defining their "moments of meeting". It is in the quiet-alert state of the newborn in which the capacity to focus attention is present and in which the phenomenon of primary intersubjectivity is encountered, depending in turn on the organization of the mother's focus of her attention on her infant. The focus of attention can be thought of as a powerful integrating function in the organizing process. (Sander, 2008, p. 185)

Gomez's ethological studies have contributed to a further understanding of the psychological meaning of the "... organization of a focus of attention as the beginning and boundary of the relation unit, arising from the total field".

\section{Body Posture Perceived in a Gestalt Way}

Many studies have evidenced the behavioral differences existing between nonhuman primates and human infants (Tomasello, 2006; Tomasello \& Camaioni, 1997).

Apes want to obtain something, whereas human infants want to share experience. Differences between apes and human infants are also observed with respect to the "... coordination of the attention around a common focus of interest". A gorilla wanting to get something takes a person's hand and directs it toward a target, having to "... call and check the attention of the human..." while doing so. The human infant engages the partner's attention with different behaviors and is able to perceive the partner's focus of attention (Gomez, 1998). ${ }^{3}$

... an infant pointing to an object strives to make the person look at the object the infant is already looking at. Conversely, an infant following the gaze of an adult is discovering and sharing this person's focus of attention. (...)

Then, when an organism perceives attention in others, it perceives something that physically is not there. This need not mean, however, that the perceiver carries out inferences about the mental attitudes underlying the other's behaviour. (Gomez, 1998, p. 249; p. 256)

As Gomez points out, attention is not a physical property of the organism, but an attitude that the subject displays toward the external world.

\footnotetext{
${ }^{3}$ Gomez is the only one among the three authors considered to take a position with respect to the theory of the mind. Referring to the first year of life, he states as follows: “... my proposal is that there are intersubjective functions for which TOM [ = theory of mind] mechanism are radically inadequate”(1998, p. 196).
} 
One can thus infer that human infants discriminate the "attentive" from " "inattentive" subject, by means of a practical conceptualization of different body attitudes, expressive rather than mental.

The partners' convergence is not simply a meeting of gazes but the ability to perceive the body expressivity of the other.

Long ago, Gestalt researchers established that the apprehension of Gestalt qualities - such as apparent movement - could be interpreted as a primary perceptual phenomenon, not as the product of inferences (Wertheimer, 1912). In the same sense, an infant need not infer that the eyes of the person are guided by a mental state (his interest in object X) to see his behaviour as attention to X. For example, the proto-declaring infant may be trying to provoke the attitude of attending to $\mathrm{X}$ in the other, this attitude being expressive rather then mental, i.e. more akin to bodily posture perceived in a Gestalt way - than to a mental attitude. The infant tries to affect how the other relates to an object, not how the other thinks about the object; in other words, the infant's actions are addressed at changing not the adult's re-presentation of the object but the adult's presentation to the object. This leads us back to the conflict between intellectual and emotional/expressive conception of intersubjectivity. (ibidem, p. 256)

In Gomez's statement, the reference to the apparent motion phenomenon can be considered a generic reference to the gestalt perception process.

It is worth taking this analogy into further consideration: primary intersubjectivity starts from the convergence of the focus of attention of the two partners and then progresses with the perception of a Gestalt of movement in a situation as a whole. On the contrary, natural sciences identify two persons in relation starting from the individual components.

In Wertheimer's study, two vertical bars, A and B, of the same shape and luminosity, are presented in a screen, one after the other at a fixed spatial distance. The duration of each bar presentation and the interval between the two presentations are varied.

As a function of these variable times, the perception of these stimuli is organized in the adult subjects according to three modalities:

1. as a sequence, i.e., first the $\mathrm{A}$ bar is perceived, then the B bar follows;

2. as an apparent motion, i.e., as if the same bar moved from the A location to the B location;

3. the two separately presented bars are perceived as simultaneous.

In children aged between 5 and 12 years, Meili and Tobler (1931, p. 156), found that in many conditions wherein an adult would perceive sequential presentations of stimuli, children perceived an apparent motion. 
In this perspective, Stern's forms of vitality acquire additional significance, when applied to daily life events, wherein movement is a basic Gestalt with - we can say - a specific structure and specific expressive qualities.

We can consider the sequence that becomes organized between the infant's requests and his/her mother's responses.

We can think of the simultaneity of their playing behaviors.

We can consider the apparent motion as a Gestalt of the events that can develop when a shared focus of attention occurs.

This process can at the same time include the partners' individual characteristics and be a significant component of the dynamics of attachment that develops within the dyad.

Could one extrapolate Gomez's view and consider the practical conceptualization of different bodily attitudes, such as "attentive", as an innate ability?

No data contradict this view. Rather, both Stern's studies of forms of vitality in daily life and Sander's studies support this hypothesis.

What deserves to be considered is the convergence of the two partners' foci of attention as a starting point of the relationship, of its becoming a significant "whole" within the wide range of stimuli coming from the external world.

We are moving from one-person focus for the understanding of development change in the human personality to an understanding of change in the individual as part of a larger, system process of change, within which the changing individual is but a part. Inclusiveness from this perspective requires us to include new understanding of the way the brain functions and the way its developing morphology is being shaped by the actualities of the infant's experiencing. (Sander, 2000, p. 5)

\section{Final Remarks}

First, the relevance of these studies for both psychotherapeutic approaches (Stern, 2004, 2010; Bruschweiler-Stern et al. 2010) and developmental studies (Trevarthen, 1996; Trevarthen \& Aitken, 2001) is worth mentioning. In both fields, the psychological models developed by these three authors have proved very fruitful.

In particular, the observed difficulties in tuning between the partners, both in autism and in early attention deficits, have been studied in relation to the nervous system's development in the context of the infant's experiences. This approach allows both a precocious diagnosis and precocious cures (Trevarthen $\&$ Delafield-Butt, 2013). 
Furthermore, notwithstanding their different languages, the three authors we considered share a common view. Indeed, when considered together, their results acquire further significance.

The ways in which the three authors refer to the Gestalt theory can be viewed as a progressive transition from the view of the brain as a Gestalt organizer particularly prominent in Stern - to the study of the phenomenological field, which is central for Gomez, with an intermediate position taken by Sander, who constantly tries to maintain an equilibrium between these two levels.

Louis Sander covers an ample field ranging from biological to psychological approaches, going from birth to the appearance of a reflective thought.

The researches that he and his collaborators performed have led to the identification of the interaction between newborn and caregiver as a Gestalt arising since the early days of life from the encounter of the Gestalts of the partner's biorhythms.

Daniel Stern focuses his attention on a specific developmental moment, from 3 to 6 months of age, showing how interaction is already a communication between two inner worlds.

He views the forms of vitality as the basic units of the "inner experience" of the partners in relation.

According to Gomez's observations, these forms of vitality can be considered the attitude, i.e., the structural and expressive qualities of the movement that both partners perceive in their relationship as a whole (Ganzeigenschaften says Waldvogel [1992]).

Carlos Gomes further investigates the significance of the convergent foci of attention of the two partners, already present in Sander's research, and outlines the Ganzeigenschaften perceived in the bodies of both, the newborn and the partner, as an attitude to meet the conspecific.

He thus identifies an important point to understand the dynamics of the early interpersonal relationship seen as a Gestalt.

The three authors we considered refer to the Gestalt theory in different ways.

The contradictory sentences used by Stern in defining his forms of vitality can be interpreted as a difficulty in the transition from the transphenomenal reality typical of the natural sciences to the phenomenal reality, the encountered "whole" of the Gestalt theory. On the contrary, Sander and Gomes try to determine the whole and its boundaries.

\section{Summary}

For the study of the first year of life, Sander, Stern, and Gomez each chose the adultinfant relationship as the unit of analysis; they followed its development, respectively, in 
moments of meeting, in the proto-conversation and in the focus of attention. The authors explicitly refer to the Gestalt theory and support the need to interpret the behavior of the child as part of a wider context, as the experiences of a person in relation (Galli, 2010) since birth.

Keywords: Intersubjectivity, Moments of Meeting, Affect Attunement, Joint Attention, Gestalt Theory.

\section{Primäre Intersubjektivität und Gestalttheorie}

\section{Zusammenfassung}

Zur Untersuchung des ersten Lebensjahres wählten L. Sander, D. Stern und J.C. Gomez als Analyseeinheit die Erwachsenen-Kind-Beziehung. Sie folgten deren Entwicklung jeweils in den Bereichen Momente der Begegnung, Proto-Konversation, und Fokus der Aufmerksamkeit. Die Autoren beziehen sich explizit auf die Gestalttheorie und belegen die Notwendigkeit, das Verhalten des Kindes als Teil eines breiteren Feldes zu interpretieren, nämlich von Geburt an als Erfahrungen einer Person in der Beziehung (Galli, 2010).

Schlüsselwörter: Primäre Intersubjektivität, Momente der Begegnung, ProtoKonversation, Fokus der Aufmerksamkeit, Gestalttheorie.

\section{References}

Arfelli-Galli, A. A. (2005). Prima di dire Io. AA: L'Io allo Specchio (pp. 5-18). Macerata, Italy: Simple edition. Bråten, S. (Ed.) (1998). Intersubjective communication and emotion in early ontogeny. Cambridge, MA: Cambridge University Press.

Bråten, S. (Ed.) (2007). On being moved. From mirror neurons to empathy. Amsterdam, Netherlands: John Benjamins Publishing Company.

Bruschweiler-Stern, N., Lyons-Ruth, K., Morgan, A. C., Nahum, J. P., Sander, L. W., Stern, D. N., The Boston Change Process Study Group, et al. (2010). Change in psychotherapy. A unifying paradigm. Boston, MA: Boston Change Process Study Group.

Delafield-Butt, J. T. \& Trevarthen, C. (2015). The ontogenesis of narrative: From moving to meaning. Frontiers in Psychology, 6, 1157.

Galli, G. (2010). Gestaltpsychologie und person. Wien, Austria: Krammer Verlag.

Gibson, J. J. (1979) The ecological approach to visual perception. Boston: Houghton-Mifflin.

Gomez, J. C. (1998). Do concepts of intersubjectivity apply to non-human primates? In S. Bråten (Ed.), Intersubjective communication and emotion in early ontogeny (pp. 245-259). Cambridge, MA: Cambridge University Press.

Kanizsa, G. (1987). Quasi-perceptual margins in homogenously stimulated fields'. In S. Petry \& G. E. Meyer (Eds.), The perception of illusory contours (pp. 40-49). New York, NY: Springer.

Meili, R., \& Tobler, C. (1931). Les mouvement stroboscopiques chez les enfants. Archives de Psychologie, 23, 131-156.

Prechtl, H. F. R. (1990). Qualitative changes of spontaneous movement in foetus and pre-term infants are a marker of neurological dysfunction. Early Human Development, 23, 151-159.

Sander, W. L. (2000). Where are we going in the field of the infant mental health? Infant Mental Health Journal, 21(1-2), 5-20.

Sander, W. L. (2002). Thinking differently. Principles of process in living systems and the specificity of being known. Psychoanalytic Dialogues, 12(1), 11-42.

Sander, W. L., Amadei, G, \& Bianchi, I. (Eds.) (2008). Living systems, Evolving consciousness, and the emerging person New York, NY: The Analytic Press.

Stern, D. N. (1971). A micro-analysis of mother-infant interaction: Behavior regulating social contact between a mother and her three-and-a half month old twins. Journal of the American Academy of Child Psychiatry, 10(3), 501-517. 
Stern, D. N. (2004). The present moment in psychotherapy and everyday life. New York, NY: W. W. Norton.

Stern, D. N. (2010). Forms of vitality: Exploring dynamic experience in psychology, the arts, psychotherapy, and development. New York, NY: Oxford University Press.

Stern, D. N., Jaffe, J., Beebe, B., \& Bennet, S. (1975). Vocalizing in unison and in alternation: Two modes of communication within the mother-infant dyad, in developmental psycholinguistics and communications disorders. Annals of the New York Academy of Sciences, 203, 89-100.

Tomasello, M. (2006). Why Don't Apes Point. In N. J. Enfield \& S. C. Levinson (Eds.), Roots of human sociality: culture, cognition and interaction (pp. 506-524). Oxford \& New York: Berg.

Tomasello, M., \& Camaioni, L. (1997). A comparison of the gestural communication of apes and human infants. Human Development, 40, 7-24.

Trevarthen, C. (1974). Conversation with a two-month-old. New Scientist, 230-235.

Trevarthen, C. (1996). Lateral asymmetries in infancy: Implication for the development of the hemispheres. Neuroscience and Biobehavioral Reviews, 20(4), 571-586.

Trevarthen, C., \& Aitken, J. K. (2001). Infant intersubjectivity: Research, theory, and clinical applications. Journal of Child Psychology and Psychiatry, 42(1), 3-48.

Trevarthen, C., \& Delafield-Butt, J. (2013). Autism is a developmental disorder in intentional movement and affective engagement. Frontiers in Integrative Neuroscience, 7, 49. doi:10.3389/fnint.2013.00049

Waldvogel, B. (1992). Psychoanalyse und Gestalpsychologie. Historische und theoretische Berührungspunkte. Gestalt Theory, 13, 19-48.

Wertheimer, M. (1912). Experimentelle Studien über das Sehen von Bewegungen. Zeitschrift fur Psychologie, $61,161-265$.

Anna Arfelli-Galli, born 1933 in Ravenna, studied Medicine and specialized in Neurology and Psychopathology at the University of Bologna. She was introduced to the Gestalt theory by her Advisor, the known Italian Gestaltpsycologist Renzo Canestrari. From 1971 she held the teaching of Developmental and Educational Psychology at the University of Macerata. She retired as Full professor in 2003. From 2003 to 2012 she was Director of the research Center of Developmental and Educational Psychology of the University of Macerata. Her main Research interest is the study of the firsts years of life. She has curated a book reviewing the Gestalt research on developmental psychology. In 2013, she became Emeritus member of the Internationale Gesellschaft für Gestalttheorie und ihre Anwendungen (GTA).

Adresse: Contrada Valle 24, 62100 Macerata, Italy

E-Mail: arfelli@unimc.it 